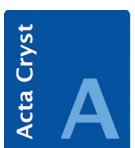

FOUNDATIONS

ADVANCES

ISSN 2053-2733

Received 16 July 2018

Accepted 16 July 2018

Keywords: X-ray scattering; attenuation correction factors; secondary scattering

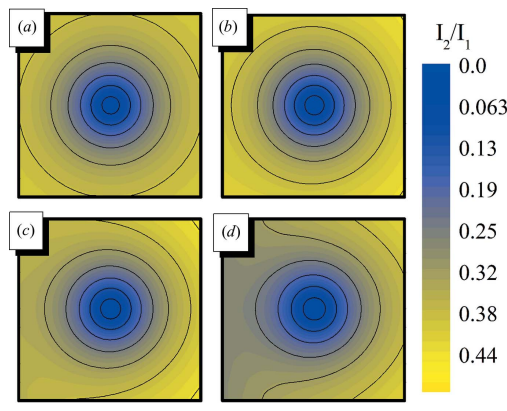

(C) 2018 International Union of Crystallography

\section{Calculation of absorption and secondary scattering of X-rays by spherical amorphous materials in an asymmetric transmission geometry. Corrigendum}

\section{J. C. Bendert,* M. E. Blodgett and K. F. Kelton}

Department of Physics, Washington University, St Louis, Missouri 63130-4899, USA. *Correspondence e-mail: jbendert@physics.wustl.edu

A revised version of Table 2 of Bendert et al. [Acta Cryst. (2013). A69, 131-139] is provided.

The expressions for $A_{i}$ for $i=3$ and 4 reported in Table 2 of Bendert et al. (2013) should be negative. The correct values are given in the table shown below.

Table 2

Coefficients for small-angle expansion of the off-axis spherical absorption.

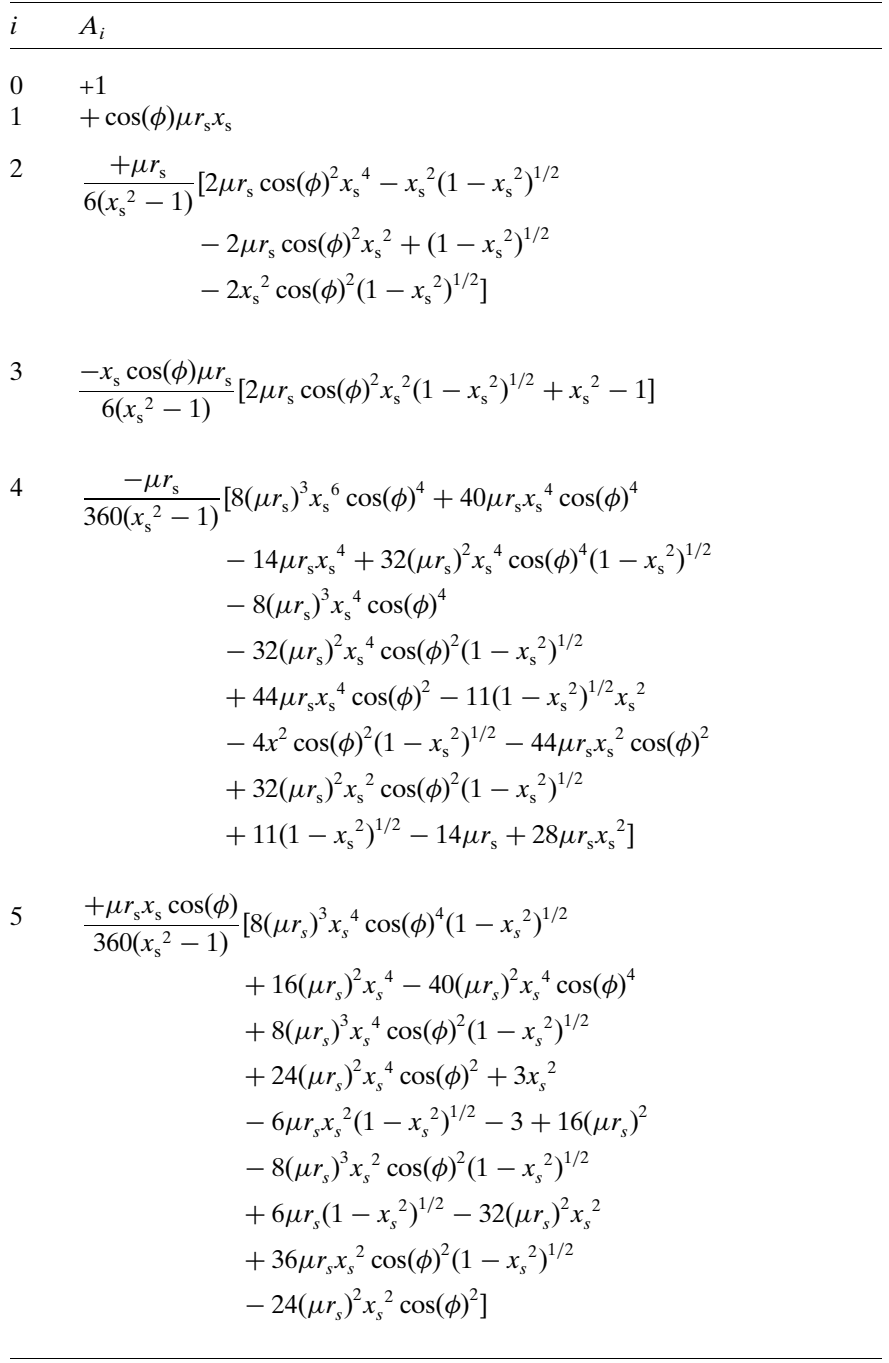

\section{References}

Bendert, J. C., Blodgett, M. E. \& Kelton, K. F. (2013). Acta Cryst. A69, 131-139. 